\title{
Performansi Sistem Pendingin Dengan Staggered Solid Dry Pad Pendingin Awal Udara Evaporator
}

\author{
Gede Biyan Mulyana ${ }^{1)}$, Hendra Wijaksana ${ }^{2}$, Ketut Astawa ${ }^{3)}$ \\ ${ }^{1)}$ Program Studi Magister Teknik Mesin Fakultas Teknik Universitas Udayana, \\ JI.P.B. Sudirman Denpasar Bali \\ ${ }^{2,3)}$ Jurusan Teknik Mesin Fakultas Teknik, Universitas Udayana Kampus Bukit Jimbaran Bali \\ Email: biyanmulyana@gmail.com, hendrawjks@gmail.com, awatsa@yahoo.com
}

doi: https://doi.org/10.24843/METTEK.2019.v05.i02.p01

\begin{abstract}
Abstrak
Performansi sistem pendingin dengan penggunaan SDP yang tersusun staggered sebagai pendingin awal udara masuk evaporator dengan memvariasikan kecepatan laju aliran massa udara diharapkan dapat memperingan kerja pada kompressor. Metode pengujian dilakukan dengan cara menguji kinerja mesin dan performan sistem pendingin dengan SDP dan tanpa SDP. Variabel yang diukur saat pengujian adalah evaporator, SDP, COP, dan daya compressor. Dari hasil penelitian didapat bahwa Performansi sistem pendingin dengan penggunaan SDP yang tersusun staggered sebagai pendingin awal udara masuk evaporator dengan menvarasikan kecepatan laju aliran massa udara, bahwa penggunaan SDP sangat berpengaruh dengan baik dalam menurunkan temperatur udara masuk sampai $17^{\circ} \mathrm{C}$ dibandingkan tanpa menggunakan SDP. Pada pemakaian SDP konsumsi daya kompresor pendinginan masing - masing mencapai $0,330 \mathrm{~kW}, 0,313 \mathrm{~kW}$ dan $0,297 \mathrm{~kW}$ lebih efektif daripada tanpa menggunakan SDP sebesar 0,363 kW. Lalu pada kapasitas pendinginan yang terbaik juga dengan penggunaan SDP sebesar 3,044 kW, 1,664 kW dan $0,879 \mathrm{~kW}$, hal ini berdampak pada hasil COP yang terbaik dengan penggunaan SDP ialah 11,6. Pada sifat udara yang dihasilkan yaitu pendinginan dan dehumidifikasi dimana udara tersebut akan didinginkan dan dikeringkan.
\end{abstract}

Kata kunci: solid dry pad, pendingin, evaporator.

\begin{abstract}
The performance of the cooling system with the use of SDP arranged staggered as the initial cooling of the air entering the evaporator by varying the speed of the air mass flow rate is expected to reduce the work on the compressor. The testing method is done by testing the engine performance and performance of the cooling system with SDP and without SDP. Variables measured during testing are evaporator, SDP, $C O P$, and compressor power. From the results of the study, it was found that the performance of the cooling system with the use of SDP arranged staggered as the initial cooling of the air entering the evaporator by varying the speed of air mass flow, that the use of SDP is very influential in reducing the air temperature to $17^{\circ} \mathrm{C}$ compared without using SDP. The use of SDP for cooling compressor power consumption reaches $0.330 \mathrm{~kW}, 0.313 \mathrm{~kW}$ and $0.297 \mathrm{~kW}$ more effectively than without using SDP of $0.363 \mathrm{~kW}$. Then at the best cooling capacity also with the use of SDP of $3.044 \mathrm{~kW}, 1.664 \mathrm{~kW}$ and $0.879 \mathrm{~kW}$, this has an impact on the COP results the best with SDP use is 11.6. In the nature of the air produced is cooling and dehumidification where the air will be cooled and dried.
\end{abstract}

Keywords: solid dry pad, cooling, evaporator

Penulis koresondensi,

Email : biyanmulyana@gmail.com, 


\section{PENDAHULUAN}

Sistem pendingin menggunakan air conditioning (AC) dan refrigrasi semakin diperlukan industri - industri untuk meningkatkan kenyamanan udara pada suatu ruangan. Pada saat ini metode refrigrasi digunakan untuk merubah temperatur udara ruangan menjadi lebih rendah daripada temperatur udara lingkungan, sehingga terjadi kenyamanan udara atau kualitas udara tersebut lebih meningkat pada suatu ruangan. Indonesia merupakan salah satu negara beriklim tropis memiliki temperatur udara berkisar $28^{\circ}-35^{\circ} \mathrm{C}$. sedangkan kondisi nyaman udara pada suatu bangunan temperature $22^{\circ} \mathrm{C}-25^{\circ} \mathrm{C}$ memiliki kelembaban Relative Humidity $40 \%-60 \%$. (ASHRAE, ASHRAE standart 62-1989 ASHRAE, Washington DC (1989)

Penggunaan AC berbasis kompressor sangat membutuhkan energi terbesar pada hotel, perumahan maupun industri - industri yang membutuhkan pendinginan sebagai kebutuhan untuk meningkatkan kualitas temperatur. Pada hal tersebut awal evaporator akan diletakan sebuah inovasi Solid Dry Pad (SDP) yang dimana pada komponen tersebut akan diberi $d r y$ ice sebagai material pendingin alternatif yang mudah didapatkan. SDP yang digunakan berupa susunan pipa secara staggered. Pada penampung atau storage dry ice akan dimana staggered bisa disebut dengan susunan zig - zag.

Berdasarkan penelitian ini akan dilakukan pengujian untuk mengurangi kebutuhan listrik pada AC dengan memberikan pendinginan awal evaporator udara masuk dengan menggunakan SDP. Dari penelitian ini material es kering sebagai pendingin yang digunakan pada dasarnya merupakan fase padat dari karbon dioksida $\left(\mathrm{CO}_{2}\right)$ yang tersusun atas dua atom oksigen terikat pada satu atom karbon. Dry ice ini merupakan bahan yang tidak mepunyai warna, tidak memiliki bau yang tidak sedap, tidak mudah terbakar dan sedikit asam. Pada suhu diatas $-56,4^{\circ} \mathrm{C}\left(-69,5^{\circ} \mathrm{F}\right)$ dan tekanan dibawah 5,2 bar, perubahan pada karbon dioksida dari fase padat ke gas tanpa bentuk cair, melalui proses yang disebut dengan sublimasi. Proses yang berlawanan disebut deposisi, dimana perubahan pada karbon dioksida dari fase gas ke fase padat . Saat tekanan atmosfer, sublimasi / deposisi terjadi ketika temperatur -78,5 ${ }^{\circ} \mathrm{C}\left(-109,3{ }^{\circ} \mathrm{F}\right)$. Kepadatan es kering bervariasi, tetapi biasanya berkisar antara sekitar 1,4 dan $1,6 \mathrm{~g} / \mathrm{cm}^{3}\left(87-100 \mathrm{lb} / \mathrm{ft}^{3}\right)$. Suhu rendah sublimasi langsung ke gas membuat es kering merupakan pendingin dengan efektivitas yang baik. Entalpi sublimasi dry ice sebesar $571 \mathrm{~kJ} /$ $\mathrm{kg}(25,2 \mathrm{~kJ} / \mathrm{mol})$. (Energy Institute London, 2010)

Dengan hal tersebut diatas, penulis ingin melakukan pengujian kembali menggunakan SDP ini diharapkan dapat memperingan kerja pada kompressor dengan melakukan pendinginan awal udara masuk evaporator. Dimana SDP tersebut terdapat material dari $d r y$ ice (Es Kering) yang efektif untuk menurunkan suhu ruangan.

\section{METODE}

\subsection{Variabel Penelitian}

Variabel bebas adalah variabel yang mempengaruhi munculnya suatu gejala. Dalam Penelitian ini variable bebas adalah pengaruh laju aliran massa udara fan menggunakan SDP yang sebesar Level I : 3,5 m/s, Level II : $5,2 \mathrm{~m} / \mathrm{s}$ dan Level III : $6 \mathrm{~m} / \mathrm{s}$.

\subsubsection{Variabel Terikat}

Variabel terikat adalah variabel yang dipengaruhi atau yang menjadi akibat karena adanya variabel bebas. Dalam penelitian ini variabel terikatnya adalah:

- $\mathrm{q}_{\mathrm{E}}$ ( evaporator )

- $\mathrm{q}_{\mathrm{SDP}}$ ( SDP )

- $\mathrm{q}_{\mathrm{K}}$ ( kondenser )

- COP (Coefficient of performance)

- W (Daya Kompressor) 
ojs.unud.ac.id/index.php/mettek

\subsection{Diagram Alir Penelitian}

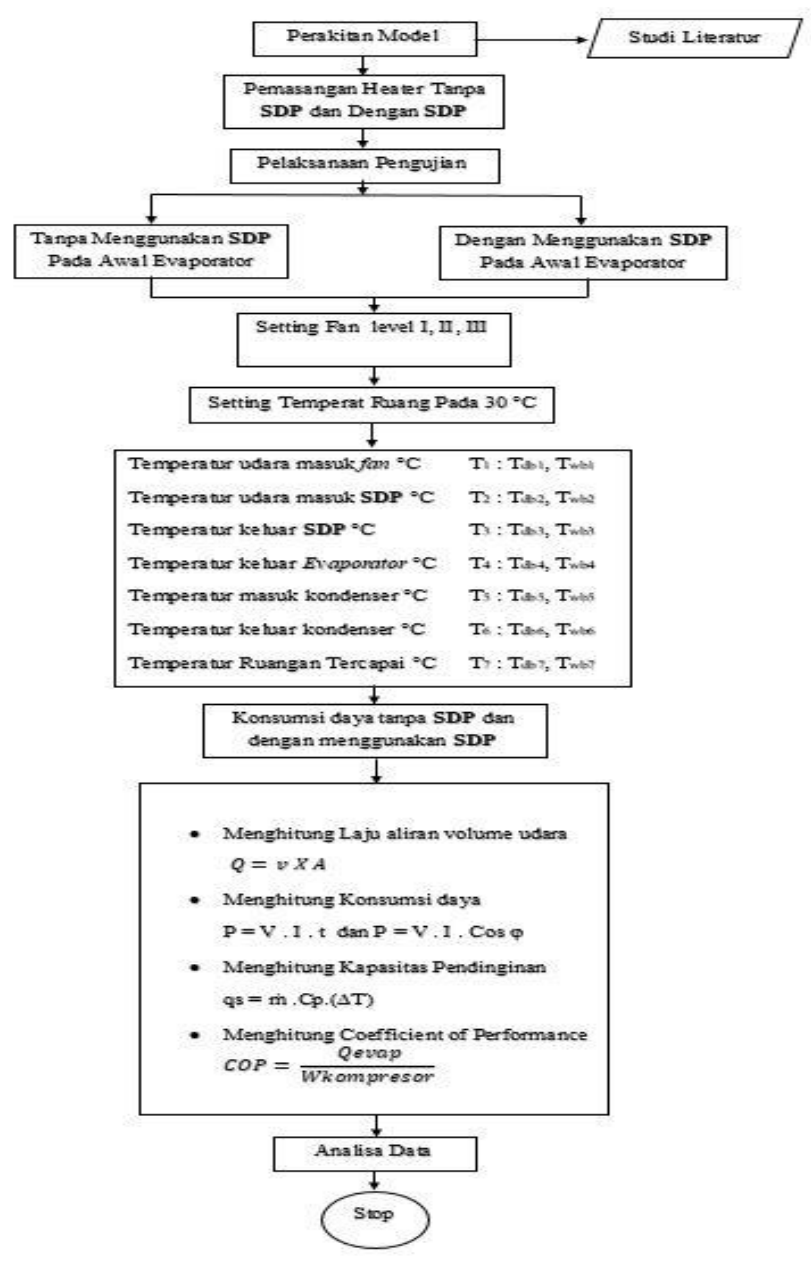

Gambar 4. Diagram alir prosedur penelitian

\section{HASIL DAN PEMBAHASAN}

\subsection{Grafik Daya Pada Kompresor}

Analisa daya kompressor pada waktu 15 menit, 30 menit, 45 menit dan 60 menit tanpa menggunakan SDP dan dengan menggunakan SDP perbandingan dapat dilihat pada gambar 4.1 dalam gambar saat waktu 60 menit tanpa penggunaan SDP memerlukan daya 0,363 kW, untuk dengan penggunaan SDP dan laju aliran massa udara $6 \mathrm{~m} / \mathrm{s}$ membutuhkan daya 0,330 $\mathrm{kW}$, sedangkan menggunakan SDP dengan laju aliran massa udara 5,2 m/s memerlukan 0,313 $\mathrm{kW}$ pada waktu 60 menit dan penggunaan SDP pada laju aliran massa udara 3,5 m/s sebesar $0,297 \mathrm{~kW}$. Semua kondisi yang terlihat dalam penggunaan SDP pada sistem air conditioning, lebih efektif untuk digunakan daripada tanpa menggunakan SDP pada sistem air conditioning. 


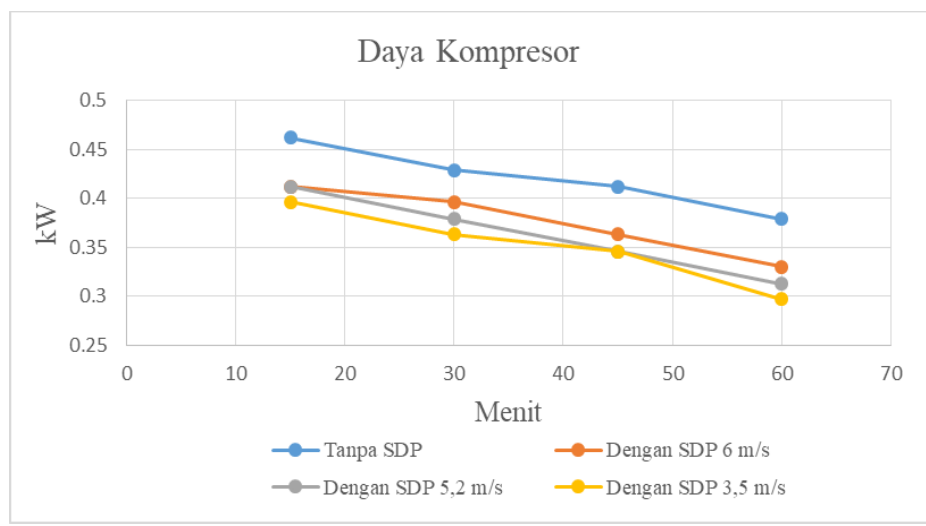

Gambar 5. Grafik kurva batang daya kompresor

\subsection{Grafik Kapasitas Pendinginan Pada Evaporator}

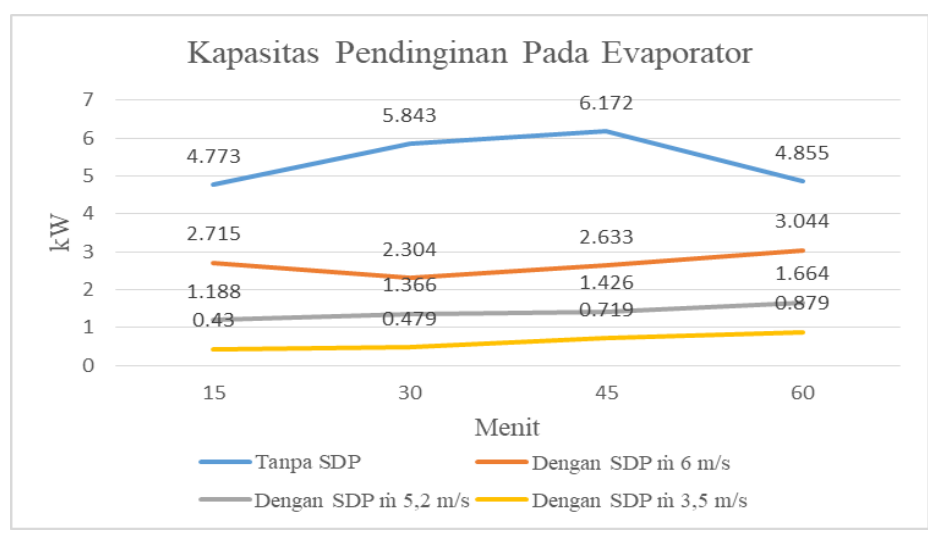

Gambar 6. Grafik kapasitas pendinginan pada evaporator

Perbandingan analisa kapasitas pendinginan evaporator saat setting tanpa SDP dan menggunakan SDP pada variasi laju aliran massa udara dapat dilihat pada gambar 4.2 untuk mencapai dalam waktu 60 menit tanpa menggunakan SDP evaporator memerlukan daya 4,855 $\mathrm{kW}$, untuk dengan SDP pada laju aliran massa udara $6 \mathrm{~m} / \mathrm{s}$ memerlukan daya 3,044 kW, saat dengan SDP laju aliran massa udara $5,2 \mathrm{~m} / \mathrm{s}$ evaporator memerlukan daya $1,664 \mathrm{~kW}$ dan dengan SDP pada laju aliran massa udara 3,5 m/s diperlukan daya sebesar 0,879 $\mathrm{kW}$. Pencapaian saat waktu 45 menit tanpa menggunakan SDP memerlukan daya 6,172 kW, dengan menggunakan SDP pada laju aliran massa udara $6 \mathrm{~m} / \mathrm{s}$ diperoleh daya 2,633 kW, pada penggunaan SDP laju aliran massa udara $5,2 \mathrm{~m} / \mathrm{s}$ daya yang digunakan $1,426 \mathrm{~kW}$ dan SDP laju aliran massa udara $3,5 \mathrm{~m} / \mathrm{s}$ dikeluarkan daya sebesar $0,719 \mathrm{~kW}$. Waktu pengujian 30 menit tanpa SDP memerlukan daya $5,843 \mathrm{~kW}$, penggunaan SDP laju aliran massa udara $6 \mathrm{~m} / \mathrm{s}$ memperoleh daya $2,304 \mathrm{~kW}$, kemudian pada SDP laju aliran massa udara $5,2 \mathrm{~m} / \mathrm{s}$ memerlukan daya $1,366 \mathrm{~kW}$ dan laju aliran massa udara 3,5 mendapatkan daya $0,479 \mathrm{~kW}$. Dan analisa percobaan terakhir pada waktu 15 menit tanpa menggunakan SDP menghasilkan daya $4,773 \mathrm{~kW}$, percobaan dengan memakai SDP pada laju aliran massa udara $6 \mathrm{~m} / \mathrm{s}$ memperoleh daya sebesar 2,715 kW, pada penggunaan SDP laju aliran massa udara $5,2 \mathrm{~m} / \mathrm{s}$ mendapatkan daya $1,188 \mathrm{~kW}$ dan pemakaian SDP dengan laju aliran massa udara 3,5 membutuhkan daya sebesar 0,430 kW. Dari semua kondisi yang terlihat dengan menggunakan SDP laju aliran massa udara $3,5 \mathrm{~m} / \mathrm{s}$ membutuhkan daya lebih sedikit daripada tanpa SDP dan variasi yang lainnya, karena penggunaan SDP tersebut mempermudah kerja pendinginan evaporator yang bertujuan meringankan kerja kompresor AC. 


\subsection{Grafik Coefficient of Performance (COP)}

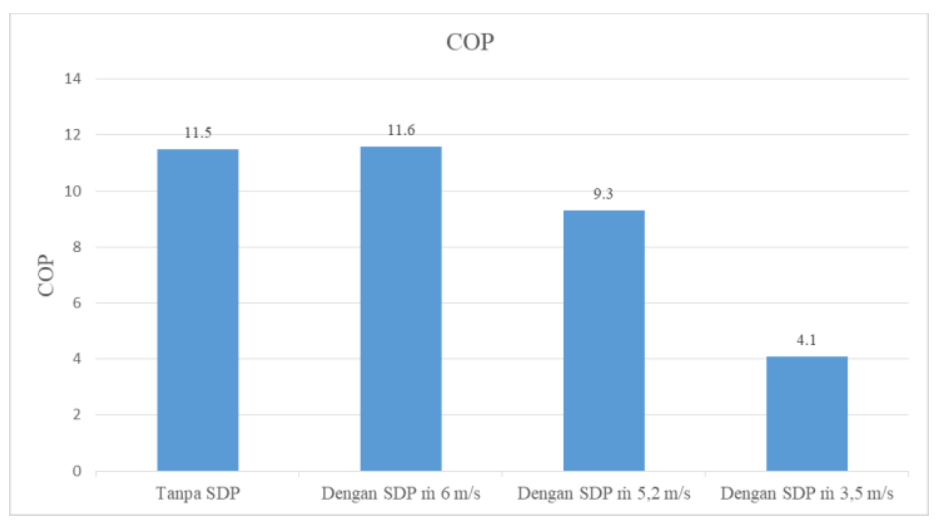

Gambar 7. Grafik coeffisient of performance

Gambar diatas mennunjukan COP pada perbandingan kecepatan, grafik tersebut menunjukan hasil yang menurun yang dapat dilihat bahwa adanya perbedaan antara COP tanpa SDP memperoleh sebesar 11,5 dan dengan menggunakan SDP dengan kecepatan aliran massa udara yang dari $6 \mathrm{~m} / \mathrm{s}$ memiliki COP sebesar 11,6 dan laju aliran massa udara $5,2 \mathrm{~m} / \mathrm{s}$ dengan 3,5 m/s meperoleh COP 9,3 dan 4,1. Dari analisa tersebut tanpa SDP dan menggunakan SDP dengan variasi kecepatan laju aliran massa udara 3,5 m/s yang mengalami penurunan yang jauh dari pada yang lainnya, karena diakibatkan penurunan kapasitas pendinginan evaporator dan penurunan kerja kompresor AC.

\section{SIMPULAN}

Adapun kesimpulan yang diperoleh dari penelitian yang telah dilakukan adalah performansi sistem pendingin dengan penggunaan SDP yang tersusun staggered sebagai pendingin awal udara masuk evaporator dengan menvarasikan kecepatan laju aliran massa udara, bahwa penggunaan SDP sangat berpengaruh dengan baik dalam menurunkan temperatur udara masuk sampai $17{ }^{\circ} \mathrm{C}$ dibandingkan tanpa menggunakan SDP. Pada pemakaian SDP konsumsi daya kompresor pendinginan masing - masing mencapai 0,330 $\mathrm{kW}, 0,313 \mathrm{~kW}$ dan 0,297 $\mathrm{kW}$ lebih efektif daripada tanpa menggunakan SDP sebesar 0,363 $\mathrm{kW}$. Lalu pada kapasitas pendinginan yang terbaik dengan penggunaan SDP sebesar 3,044 $\mathrm{kW}, 1,664 \mathrm{~kW}$ dan $0,879 \mathrm{~kW}$, hal ini berdampak pada hasil COP yang terbaik dengan menggunakan SDP ialah 11,6. Pada sifat udara yang dihasilkan yaitu pendinginan dan dehumidifikasi dimana udara tersebut akan didinginkan dan dikeringkan.

\section{DAFTAR PUSTAKA}

[1]ASHRAE. 1989. Handbook of Fundamental, Chapter 8: Physiological Principles, Comfort, and Health, ASHRAE, USA.

[2]Carrier Air Conditioning Company. 1965. Handbook of Air Conditioning System Design , McGraw-Hill Book Company, New-York.

[3]Energy Institute London. 2010. Good Plant Design And Operation For Onshore Carbon Capture Installations And Onshore Pipelines, London.

[4] Sungadiyanto. 2006. "Studi Eksperimental Performa Mesin Pengkondisian Udara (AC) MC Quay Dengan Refrigerant R-22" Universitas Semarang.

[5] Stoecker W.F, Jones J.W. 1982. Refrigerasi dan Pengkondisian Udara, Airlangga, Jakarta. 